\title{
Abordagem ecológica para avaliação dos determinantes de comportamentos preventivos: proposta de inventário aplicado aos músicos
}

\author{
Thaís Branquinho Oliveira Fragelli (UnB, Brasilia, DF) \\ tbranquinho@unb.br
}

Isolda de Araújo Günther (UnB, Brasília, DF)

isolda@unb.br

Resumo: 0 presente trabalho teve por objetivo construir um inventário para avaliar os determinantes do comportamento saudável presente nos ambientes social e físico, relacionado à prevenção de lesões ocupacionais em músicos. 0 processo de construção do inventário baseou-se nas diretrizes para construção de instrumentos psicológicos preconizadas por PASQUALI (1999) e na conceituação formulada pela perspectiva ecológica. A partir desse referencial propõe-se um modelo para analisar o comportamento preventivo fundamentado em três componentes: a) as crenças de profissionais da música sobre o comportamento preventivo; b) uma avaliação das condições de trabalho disponibilizadas nos espaços para a prática musical; c) e a influência social no meio musical.

Palavras-Chave: lesões ocupacionais; saúde do músico; comportamento saudável.

Ecological approach to evaluate of preventive behavior: proposal of an inventory applied to musicians

Abstract: This study aimed at developing an inventory to assess social and physical environments determinants that influence the healthy behavior related to prevention of occupational injuries in musicians. The process of constructing the inventory is based on the guidelines for construction of psychological instruments by PASQUALI (1999) and the concept formulated by the ecological perspective. From this theoretical standpoint it is proposed a model to examine the preventive behavior based on three components: a) the beliefs of musicians on preventive behavior, b) an assessment of working conditions available in space for music practice, c) and social influence in the musical environment.

Keywords: occupational injuries; musicians' health; health behavior.

\section{Introdução}

0 interesse de pesquisadores pelos comportamentos saudáveis busca entender os determinantes desses, bem como o processo de escolha de tais comportamentos. Tal conhecimento auxilia no desenvolvimento e na implementação de intervenções em saúde pública para indivíduos e comunidades (NOAR; ZIMMERMAN, 2005).

Comportamentos saudáveis são definidos como qualquer atividade empreendida para proporcionar prevenção e/ou detecção de doença ou a melhoria da saúde e do bemestar (CONNER; NORMAN, 1996). Nesta perspectiva, considera-se que as lesões podem ser prevenidas por meio de mudanças no comportamento e baseadas em pesquisas que esclareçam a maneira como se processam as escolhas desses comportamentos, fator de suma importância na manutenção, melhoria e recuperação da saúde (GIELEN; SLEET, 2003). As consequências desse procedimento podem implicar na redução de custos médicos e de mortes prematuras (GLANZ; LEWIS; RIMER, 1997).

Vários são os modelos propostos para entender como se processam as escolhas dos comportamentos saudáveis preventivos e de seus determinantes, no entanto, a perspectiva ecológica se apresenta como 
uma abordagem abrangente que tenta explicar como o ambiente influencia o comportamento e como a pessoa influencia o ambiente (SALLIS; OWEN,1997). Para compreender o paradigma ecológico faz-se necessário um envolvimento multidisciplinar que possibilite analisar a natureza da interrelação das pessoas com seu ambiente físico e sociocultural. Esta abordagem tem contribuído para a elaboração de estratégias de promoção de saúde e de intervenção com a finalidade de contribuir para o bem estar do indivíduo (STOKOLS, 1992). De acordo com STOKOLS (1992), o ambiente, pode ser compreendido por meio de quatro perspectivas:

i. A salubridade de uma situação e o bem estar dos indivíduos são influenciados pelos ambientes físico e social acrescido de atributos pessoais. Assim sendo, a dinâmica pessoa vs. ambiente é entendida por meio da interrelação entre fatores ambientais e pessoais;

ii. Ambientes podem ser descritos a partir de vários significados como: físico e/ou social; o objetivo (real) e/ou o subjetivo (percebido); pelos atributos (temperatura, espaço) e, finalmente, por construtos teóricos (behavior setting ou clima social);

iii. .0 estudo pode ocorrer nos níveis do indivíduo, dos pequenos grupos, das organizações ou de amostras da população;

iv. As pessoas influenciam seus ambientes e estes, por sua vez, exercem alguma influência sobre o comportamento de saúde das pessoas.

\section{Comportamentos saudáveis relacionados à prevenção de lesões ocupacionais musculoesqueléticas}

Segundo WHITING e ZERNICKE (2001) considera-se lesão musculoesquelética qualquer dano causado por trauma físico sofrido pelos tecidos do corpo. Esses autores também afirmam que as lesões são acompanhadas de custos físicos, emocionais e econômicos, como por exemplo, a perda de tempo e da função normal.

Neste contexto, com uma visão no futuro, programas de prevenção têm sido implementados em empresas com objetivo de reduzir os encargos referentes aos custos médicos, de obter maior satisfação de seus funcionários e de melhorar a produtividade. Dentre as estratégias básicas adotadas no controle e na prevenção de lesões incluem-se as mudanças no comportamento para a adoção de hábitos saudáveis dentro das organizações (WHITING; ZERNICKE, 2001), como por exemplo, os comportamentos de uso de equipamentos de proteção individual, a adoção de técnicas de alongamentos e de postura corporal adequada.

A postura corporal, definida como uma posição do corpo para uma determinada atividade ou a maneira como se sustenta o corpo (LEHMKUL; SMITH apud KISNER;
COLBY, 1992), é um fator importante na preservação das estruturas musculoesqueléticas, sendo apontada por pesquisadores como um requisito para o sucesso em programas preventivos (BRACCIALLI; VILARTA, 2000). Assim, considera-se importante as orientações, não apenas quanto ao uso do mobiliário no trabalho estático, aquele em que há contração contínua para manter determinada posição, mas também quanto a ter uma boa postura corporal no trabalho dinâmico, aquele em que há a alternância entre contração e relaxamento muscular (IIDA, 2003).

A adoção de postura corporal inadequada ou antifisiológica contribui para um envelhecimento precoce das estruturas (NASCIMENTO; MORAES, 2000) e relaciona-se à etiologia das lesões ocupacionais musculoesqueléticas. 0 tempo máximo de permanência em certas posturas denominadas inadequadas, até que se iniciem sintomas pode variar entre um a cinco minutos (IIDA, 2003).

Outro comportamento que as pesquisas relacionam como fator que contribui para a saúde musculoesquelética refere-se à adoção de exercício ou ginástica laboral, envolvendo, basicamente, exercícios de alongamento (MARTINS; MICHELS, 2001).

Os indivíduos que apresentam um melhor condicionamento físico e uma maior flexibilidade possuem menor probabilidade de sofrerem lesões e maior capacidade de recuperação após terem sofrido alguma lesão. Assim, 0 alongamento regular pode contribuir para a prevenção de lesões, para redução da rigidez articular, para redução da retração de músculos e de tendões e, consequentemente, da dor muscular relacionada ao exercício da atividade (WHITING; ZERNICKE, 2001), ao mesmo tempo que possibilita a manutenção da flexibilidade e diminui o risco de doenças ocupacionais (NASCIMENTO; MORAES, 2000).

\section{Perspectiva ecológica: referencial teórico}

A perspectiva ecológica propõe que os comportamentos são influenciados por variáveis intrapessoais ou individuais, socioculturais e do ambiente físico e que estas variáveis interagem entre si (SALLIS; OWEN, 1997).

\subsection{Fatores intrapessoais}

Segundo o modelo de crenças em saúde, a avaliação do comportamento é composta por duas crenças, sendo uma relacionada aos benefícios ou eficácia do comportamento de saúde recomendado, e outra relacionada aos custos ou barreiras para executar 0 comportamento (SHEERAN; ABRAHAM, 1999; CONNER, 2002) traduzindo, portanto, uma relação custo/benefício. Segundo DELA COLETA (2004) a percepção dos benefícios decorrentes do comportamento é condição necessária, porém não suficiente, para a adesão voluntária. Assim, para este modelo desenvolvido nesse artigo foram consideradas as crenças nos comportamentos preventivos com o objetivo de observar a avaliação do comportamento, traduzindo uma relação custo/ benefício conforme relacionado anteriormente. No que 
tange a esse aspecto, parece ser plausível que as pessoas tendam a adotar comportamentos que acreditem trazer benefícios para si que, por sua vez, devem ser percebidos como capazes de superar as barreiras para a adoção de um comportamento adequado.

\subsection{Fatores socioculturais}

A Organização Mundial de Saúde (OMS) considera que os comportamentos são socialmente determinados e que a escolha dos mesmos é realizada a partir das alternativas disponíveis aos indivíduos e das facilidades inerentes à escolha. Dessa maneira, os comportamentos não são estáticos, estando na dependência do processo de socialização, i. e, da influência dos pais, familiares, amigos, dos professores, constituindo assim, um processo dinâmico, sempre baseado na re-interpretação (OLIVEIRA, 2005) e re-significação da situação. Segundo STOKOLS (1992), é importante observar o contexto social onde o individuo vive e/ou trabalha. A compreensão do impacto social relacionado ao comportamento saudável contribui para o planejamento de uma intervenção efetiva com condições de prevenir ou reduzir os riscos de adoecimento (HEANEY, ISRAEL, 1997).

\subsection{Ambiente físico}

STOKOLS (1992) adverte que a salubridade de uma situação e o bem-estar dos participantes são influenciados não só pelo ambiente social, mas também pelo ambiente físico. Nessa perspectiva, o ambiente físico pode conter fatores que favorecem ou dificultam a adoção e/ou mudança de comportamentos.

As condições de trabalho precárias como, por exemplo, equipamentos e/ou postos ergonomicamente inadequados podem estar associados a níveis mais elevados de perigo ou de risco físico. Acrescentam-se ainda os níveis inadequados de temperatura, de ruído e ou jornadas de trabalho estafantes e contínuas, que influenciariam diretamente a saúde e o bem-estar dos trabalhadores (STOKOLS, 1992; GRZYWACZ , FUQUA, 2000).

\section{Método}

\subsection{Etapas de validação do inventário}

0 processo de construção do presente inventário envolveu três etapas. A primeira etapa consistiu na formulação e escolha dos itens. Em seguida, os itens foram submetidos à análise semântica a um grupo de quatro músicos, com a finalidade de verificar sua pertinência, a compreensão e a adequação da linguagem a ser utilizada no estudo da população alvo. Prosseguindo, o inventário foi exposto à análise de quatro juízes para verificar o conteúdo, a formatação e para definir a melhor disposição dos itens. Como resultado desta primeira análise, alguns itens foram incluídos, outros alterados substancialmente, modificados ou excluídos.

Na segunda etapa, foi realizado um estudo piloto com 17 músicos com o objetivo de refinar o inventário e submetê-lo a uma segunda avaliação semântica, para eliminar possíveis dúvidas que pudessem surgir no ato da aplicação.

$\mathrm{Na}$ terceira etapa, o inventário foi aplicado a uma amostra de 136 músicos com a finalidade de testar seu potencial empírico.

0 instrumento que resultou desse processo é composto por uma escala de crenças de profissionais de música sobre o comportamento preventivo; uma avaliação das condições de trabalho dos espaços para a prática musical; uma escala da influência social no grupo musical.

A escala que diz respeito às crenças de profissionais de música sobre o comportamento preventivo foi composta por 20 itens, com amplitude de cinco pontos, a saber: 1- "Discordo totalmente"; 2- "Discordo"; 3- "Nem concordo nem discordo"; 4- "Concordo" e, 5- "Concordo totalmente". Buscou-se refletir nessa escala as dimensões teóricas, os benefícios e as barreiras, para realização dos passos envolvidos no alongamento, na adoção de uma postura corporal adequada, dimensões descritas no modelo proposto pela perspectiva ecológica.

A escala de condições de trabalho dos espaços para a prática musical foi composta por 12 itens igualmente com amplitude de cinco pontos. Entretanto foi utilizada uma escala de frequência comparando os diferentes espaços de ensaio do instrumentista, considerando não apenas os encontros regulares com o grupo, que abrangeu as seguintes categorias: 1- "Nunca"; 2- "Raramente"; 3"Ocasionalmente"; 4- "Frequentemente" e 5- "Sempre".

A escala de influência social no grupo musical foi composta por 21 itens com amplitude de cinco pontos: 1- "Discordo totalmente"; 2- "Discordo"; 3- "Nem concordo nem discordo"; 4- "Concordo" e, 5- "Concordo totalmente". Elaborou-se o instrumento de maneira que as dimensões propostas no modelo estivessem refletidas em seus itens.

\subsection{Participantes}

A amostra foi do tipo não-probabilística, composta por 136 músicos profissionais.

Foram visitados nove grupos de instituições do Distrito Federal e do estado de Goiás, perfazendo um total de 254 questionários distribuídos. Destes, 136 questionários retornaram sendo 112 de respondentes do sexo masculino e 22 do sexo feminino. A média de idade foi de 37,92 anos $(d p=10,20)$. Dentre os respondentes dezenove são saxofonistas, sendo os instrumentistas os mais representativos da amostra. 0 tempo de prática diária variou entre uma e oito horas.

0 número de anos de prática do instrumento variou entre um e 44 anos e o tempo de atuação no grupo, entre um e 28 anos.

0 resumo dos dados demográficos é apresentado no Ex. 1. 


\begin{tabular}{|c|c|c|c|c|c|}
\hline \multicolumn{2}{|l|}{ Variável } & \multirow{2}{*}{$\frac{f}{112}$} & \multirow{2}{*}{$\begin{array}{c}\% \\
82,4\end{array}$} & \multirow[t]{2}{*}{ Média } & \multirow[t]{2}{*}{ DP } \\
\hline Sexo & Masculino & & & & \\
\hline Jex & Feminino & 22 & 16,2 & & \\
\hline \multirow{3}{*}{ Estado Civil } & Solteiro & 46 & 33,8 & & \\
\hline & Casado & 76 & 55,9 & & \\
\hline & Divorciado & 12 & 8,8 & & \\
\hline \multicolumn{2}{|c|}{ Idade (anos) Amplitude de 18 a 66} & & & 37,92 & 10,20 \\
\hline \multirow{6}{*}{ Escolaridade } & Fundamental & 1 & 0,7 & & \\
\hline & Médio & 45 & 33,1 & & \\
\hline & Superior incompleto & 34 & 25 & & \\
\hline & Superior completo & 38 & 27,9 & & \\
\hline & Pós-graduação incompleta & 4 & 2,9 & & \\
\hline & Pós-graduacão completa & 11 & 8,1 & & \\
\hline \multirow{19}{*}{ Instrumento } & Baixo Elétrico & 1 & 0,7 & & \\
\hline & Bombardino & 2 & 1,5 & & \\
\hline & Clarineta & 17 & 12,5 & & \\
\hline & Clarone & 1 & 0,7 & & \\
\hline & Contrabaixo & 5 & 3,7 & & \\
\hline & Fagote & 3 & 2,2 & & \\
\hline & Flauta & 7 & 5,1 & & \\
\hline & Oboé & 2 & 1,5 & & \\
\hline & Percussão & 11 & 8,1 & & \\
\hline & Saxofone & 19 & 14 & & \\
\hline & Teclado & 1 & 0,7 & & \\
\hline & Trombone & 12 & 8,8 & & \\
\hline & Trompa & 4 & 2,9 & & \\
\hline & Trompete & 8 & 5,9 & & \\
\hline & Tuba & 3 & 2,2 & & \\
\hline & Viola & 9 & 6,6 & & \\
\hline & Violão & 4 & 2,9 & & \\
\hline & Violino & 14 & 10,3 & & \\
\hline & Violoncelo & 10 & 7,4 & & \\
\hline \multicolumn{2}{|c|}{ Tempo de Prática horas/dia: 1 a 8} & & & 3,67 & 1,32 \\
\hline \multicolumn{2}{|l|}{ Anos: 1 a 44} & & & 16,45 & 9,63 \\
\hline \multicolumn{2}{|c|}{ Tempo de atuação no grupo ( 1 a 28 anos) } & & & 9,02 & 7,88 \\
\hline
\end{tabular}

Ex.1 - Tabela com dados demográficos

\section{Resultados}

5.1.Primeira escala: crenças de profissionais da música sobre comportamento preventivo

0 primeiro passo foi verificar, por meio da análise dos componentes principais, se a matriz era fatorizável. Para tanto, alguns critérios foram considerados, como 0 Kayser-Meyer-Olkin (KMO) que postula que a matriz é tanto mais fatorizável quanto mais próximo de 1 (um), indicando, desta forma, que as variáveis têm muito em comum. 0 resultado do KMO foi 0,762, considerado mediano na classificação de Kaiser (PASQUALI, 2005). Outra avaliação realizada foi a do teste de esfericidade de Bartlett, na qual o qui-quadrado demonstrou um valor significativo. 0 resumo dos resultados pode ser visualizado no Ex.2.

Para decidir o número de fatores a ser extraído da matriz efetuou-se a análise dos componentes principais, cujo resultado evidenciou dois dados relevantes: (1) o 


\begin{tabular}{lcc}
\hline Índices & Valor & sig \\
\hline KMO & 0,762 & \\
Teste de esfericidade de Bartlett's & 591,653 & 0,000 \\
Determinante & 0,008 & \\
\hline
\end{tabular}

Ex. 2 - Tabela com análise de componentes principais de fatorabilidade para a escala crença de profissionais da música sobre comportamento preventivo

\begin{tabular}{|c|c|c|}
\hline \multirow{2}{*}{ Variáveis } & \multicolumn{2}{|c|}{ Cargas fatoriais } \\
\hline & Fator1 & Fator2 \\
\hline A condição física melhora com alongamentos & 0,68 & \\
\hline Alongamentos melhoram o desempenho & 0,64 & \\
\hline Há redução de estresse quando se faz alongamento & 0,60 & \\
\hline 0 desempenho no ensaio melhora quando se adota boa postura corporal & 0,57 & \\
\hline Ter boa postura corporal ao tocar facilita os movimentos & 0,56 & \\
\hline Ter uma boa postura corporal ao tocar preserva a saúde & 0,59 & \\
\hline Fazer alongamentos evita o aparecimento de dor & 0,51 & \\
\hline Alongamentos deixam os músculos flexíveis & 0,50 & \\
\hline Alongamentos são somente para quem tem tempo & $-0,44$ & \\
\hline Somente quando se sente dor é necessário alongar & $-0,42$ & \\
\hline Manter uma boa postura corporal ao tocar é cansativo & $-0,40$ & \\
\hline Uma boa postura corporal ao tocar evita o aparecimento de dor & 0,40 & \\
\hline Fazer alongamentos provoca cansaço & $-0,33$ & \\
\hline 0 peso do instrumento dificulta a manutenção de boa postura & & 0,64 \\
\hline Nem sempre é possivel manter boa postura corporal ao tocar & & 0,63 \\
\hline Sinto dor quando tento melhorar a postura corporal ao tocar & & 0,51 \\
\hline 0 uniforme dificulta os movimentos ao tocar & & 0,43 \\
\hline É difícil conciliar a técnica do instrumento com boa postura & & 0,42 \\
\hline Número de itens & 13 & 5 \\
\hline Autovalores & 4,519 & 2,129 \\
\hline \% variância & 22,593 & 10,647 \\
\hline Alpha & 0,82 & 0,65 \\
\hline
\end{tabular}

\% variância acumulada 33,240

Ex.3 - Tabela com resumo da análise fatorial do instrumento sobre crenças de profissionais de música sobre o comportamento preventivo

determinante 0,008 que, por ser um valor próximo a zero, indica um número pequeno de fatores; (2) a análise dos eigen values maior ou igual a 1. PEREZ-NEBRA (2005), no entanto, recomenda o critério de corte acima de dois, para maior confiabilidade do fator, mesmo que neste caso ocorra menor variância explicada.

Após esta análise exploratória e de posse dos dados de fatorabilidade, uma vez sabida sua viabilidade de rotação e fatoração, foi realizada a análise de principal axis factoring (PAF) com rotação oblíqua, por permitir que os fatores apareçam correlacionados respeitando os fenômenos, uma vez que não há suporte teórico para esperar que os fenômenos sejam independentes entre si (PASQUALI, 2005).

Realizou-se também, a análise da consistência interna, por meio do coeficiente alpha de Cronbach. 0 resumo das análises será apresentado no Ex.3. 


\subsection{Segunda escala: condições de trabalho dos espaços para a prática musical}

Efetuou-se a análise exploratória por meio da análise dos componentes principais e, de posse dos dados de fatorabilidade foi realizado o procedimento de principal axis factoring (PAF) uma vez que esta análise produz estimativas precisas das cargas fatoriais, embora sem rotação, já que esta escala se apresentou como sendo unifatorial (Ex.4 e Ex.5).

\begin{tabular}{lcc}
\hline Índices & Valor & sig \\
\hline KMO & 0,748 & \\
Teste de esfericidade de Bartlett's & 327,390 & 0,000 \\
Determinante & 0,075 & \\
\hline
\end{tabular}

Ex. 4 - Tabela com resultados da análise de componentes principais de fatorabilidade para a escala condições de trabalho dos espaços para prática musical.

\begin{tabular}{l|c}
\hline & $\begin{array}{c}\text { Cargas } \\
\text { fatoriais }\end{array}$ \\
\cline { 2 - 2 } Variáveis & Fator \\
\hline Temos espaço físico para realizar alongamentos no meu local de ensaio & $-0,32$ \\
A má iluminação do ambiente induz a uma postura corporal inadequada para conseguir enxergar & 0,35 \\
Dividir a estante com outro colega afeta meu conforto físico & 0,60 \\
Partitura de má qualidade induz a uma postura corporal inadequada para conseguir enxergar & 0,44 \\
A acústica do ambiente faz com que eu tenha que me esforçar para conseguir me ouvir & 0,63 \\
A temperatura do ambiente de ensaio deixa minhas articulações mais rígidas & 0,71 \\
Dividir a estante com outro colega dificulta a manutenção de uma boa postura corporal & 0,75 \\
A proximidade entre os naipes faz com que eu tenha que me esforçar para conseguir me ouvir & 0,60 \\
\hline Número de itens & 8 \\
Autovalores & 3,305 \\
Alphariância & 27,540 \\
\hline
\end{tabular}

Ex. 5 -. Tabela com resumo da análise fatorial da escala de condições de trabalho dos espaços para prática musical

\subsection{Terceira escala: influência social no grupo musical}

Foram efetuadas as mesmas análises anteriores e, de posse dos dados de fatorabilidade, foi realizada a rotação conforme apresentado no Ex.6 e Ex.7.

\begin{tabular}{lcc}
\hline Índices & Valor & sig \\
\hline KMO & 0,784 & \\
Teste de esfericidade de Bartlett's & 899,112 & 0,000 \\
Determinante & 0,001 & \\
\hline
\end{tabular}

Ex. 6 - Tabela com resultados da análise de componentes principais de fatorabilidade para a escala influência social no grupo musical 


\begin{tabular}{|c|c|c|}
\hline \multirow{2}{*}{ Variáveis } & \multicolumn{2}{|c|}{ Cargas fatoriais } \\
\hline & Fator 1 & Fator2 \\
\hline Sou incentivado pelo grupo a realizar alongamentos & 0,77 & \\
\hline As informaç̧̃es sobre prevenção de dor que recebo no grupo são satisfatórias & 0,66 & \\
\hline Temos treinamentos no grupo sobre prevenção de dor no trabalho & 0,65 & \\
\hline Sou incentivado pelo grupo a manter uma boa postura corporal & 0,64 & \\
\hline Todos fazem pausas no ensaio para realizar alongamentos & 0,59 & \\
\hline Temos acesso no grupo à informação sobre como podemos nos prevenir de dor ao tocar & 0,57 & \\
\hline 0 grupo se preocupa em trocar informações sobre alongamentos & 0,56 & \\
\hline 0 grupo se preocupa em aquecer os músculos antes do ensaio & 0,53 & \\
\hline 0 grupo tem a preocupação em trocar informações sobre boas posturas & 0,45 & \\
\hline 0 grupo se preocupa em ter uma boa postura corporal durante a atividade & 0,31 & \\
\hline Os colegas acreditam que boas posturas nos ensaios podem prevenir dor & & 0,81 \\
\hline Para o grupo a saúde do corpo é importante para o desempenho & & 0,75 \\
\hline Os colegas acreditam que alongamentos nos ensaios podem prevenir dor & & 0,55 \\
\hline Para o grupo, a profissão de músico exige medidas preventivas de lesões & & 0,51 \\
\hline Existe preocupação dos colegas em realizar atividades para prevenir a dor ao tocar o instrumento & & 0,44 \\
\hline Para o grupo, manter a saúde do corpo é tão importante quanto ter um bom instrumento musical. & & 0,41 \\
\hline Número de itens & 10 & 6 \\
\hline Autovalores & 5,095 & 2,454 \\
\hline \% variância & 24,264 & 11,686 \\
\hline Alpha & 0,85 & 0,77 \\
\hline
\end{tabular}

\% variância acumulada 35,951

Ex.7 - Tabela com resumo da análise fatorial da escala de influência social no grupo musical

\section{Discussão}

As análises efetuadas revelam que os três componentes das escalas e o conteúdo de seus itens refletem as dimensões teóricas que fundamentaram a construção do inventário. Assim, considerando a escala de crenças de profissionais de música sobre comportamento preventivo, os itens pertencentes ao fator 1 relacionam a teoria de crenças dos benefícios que o comportamento preventivo pode oferecer, considerando que as cargas fatoriais mais altas têm maior influência sobre a interpretação dos fatores (HAIR, ANDERSON, TATHAM, BLACK, 2005). Os resultados dos quatro itens com carga de sinal oposto podem ser interpretados como uma correlação negativa com os demais itens, indicando, portanto, a mesma direção do fator (PASOUALI, 2005). Por sua vez, os itens do fator 2, correspondem às barreiras enfrentadas na realização dos comportamentos preventivos. Foram eliminados dois itens: "Fazer alongamentos exige grande esforço" e "A dor pode ser causada por alongamentos", uma vez que apresentaram cargas inferiores a 0,30.

A análise da escala de condições de trabalho dos espaços para a prática musical indicou um fator único no que se refere às condições de trabalho. Quatro itens foram eliminados por apresentarem carga inferior a 0,30. São eles: "A altura da cadeira favorece uma boa postura corporal"; "A altura das estantes pode ser regulada de acordo com a minha necessidade"; "0 espaço entre as cadeiras é suficiente para que eu me sinta confortável" e "0 apoio do encosto favorece uma boa postura corporal".

Quanto à escala de influência social no grupo musical os itens que compõem o fator 1 mostraram relação com os comportamentos compartilhados pelo grupo. Por outro lado, os resultados dos itens do fator 2 corresponderam às normas subjetivas quanto ao comportamento preventivo. Foram excluídos cinco itens por apresentarem carga inferior a 0,30. São eles: "É importante para o grupo ter orientações sobre boa postura corporal"; "Há poucas oportunidades para trocar ideias com colegas sobre prevenção de dor"; "Há falta de apoio no grupo para implementação de projetos de prevenção de dor"; "Alongamentos para desempenhar a atividade de tocar atrapalham o grupo" e "Realizar pausas para alongamentos no ensaio provoca reações negativas dos colegas". 
Nesta análise foram obtidos alpha de Cronbach em niveis considerados adequados o que é indicativo de validade interna. De acordo com o referencial teórico, também foram obtidas dimensões que refletiram aspectos tanto do ambiente físico quanto do ambiente social.

Uma limitação observada no esforço de validação do presente inventário, diz respeito à sua generalização, uma vez que, em face da pouca representatividade dos participantes alerta-se que os resultados ficam restritos à amostra estudada, indicando a necessidade de testes em amostras representativas.
Uma segunda limitação refere-se à terminologia utilizada que necessita de adaptações para se adequar ao grupo a ser pesquisado. Recomenda-se, por conseguinte, que os possíveis refinamentos semânticos realizados em estudos futuros levem em conta a necessidade da utilização desse inventário em profissionais músicos de diferentes modalidades instrumentais e atuando em diferentes contextos.

Em sintese, esse artigo apresentou um instrumento que se propõe a estudar os fatores determinantes de comportamentos preventivos, específicos para a população de músicos.

\section{Referências}

BRACCIALLI, LMP; VILARTA, R. Aspectos a Serem Considerados na Elaboração de Programas de Prevenção e Orientação de Problemas Posturais. Revista Paulista de Educação Física, 14(2), 2000, 159-171.

CONNER,M. Health Behaviors. Disponivel em: http://userpage.fu-berlin.de/ schuez/folien/conner2002. pdf. Acessado em: 14/11/2006, 2002.

CONNER, M; NORMAN, P. The Role of Social Cognition in Health Behaviors. In: CONNER, M; NORMAN, P (eds). Predicting Health Behavior (pp 1 - 22). Philadelphia: Open University Press, 1996.

DELA COLETA, MF(Org). Modelos para pesquisa e modificação de comportamentos de saúde: teorias, estudos e instrumentos. Taubaté: Cabral, 2004.

GIELEN, AC; SLEET, D. Application of Behavior-Change Theories and Methods to Injury Prevention. Epidemiologic Reviews, 25, 2003, 65-76.

GLANZ, K; LEWIS, FM; RIMER, BK. The scope of health promotion and health education. In GLANZ, K; LEWIS, FM; RIMER, BK (eds), Health Behavior and Health Education (pp. 3- 18). San Francisco: Jossey Bass, 1997.

GRZYWACZ, JG; FUQUA, J. The social ecology of health: leverage points and linkages. Behavioral Medicine, 26(3),101-116, 2000.

HAIR, JF; ANDERSON, RE; TATHAM, RL BLACK, WC. Análise fatorial. In: Em J HAIR, JF; ANDERSON, RE; TATHAM, RL BLACK, WC. Análise multivariada de dados (pp. 89-124). Porto Alegre: Bookman, 2005.

HEANEY, CA; ISRAEL, BA. Social Networks and Social Support. In: GLANZ, K; LEWIS, KF, RIMER, BK (eds), Health Behavior and Health Education (pp. 179- 205). San Francisco: Jossey Bass, 1997.

IIDA, I. Ergonomia Projeto e Produção. São Paulo: Edgard Bluncher, 2003.

KISNER, C; COLBY, LA. A Coluna: postura. In KISNER, C; COLBY, LA Exercícios Terapêuticos: Fundamentos e Técnicas (pp.429- 471). São Paulo: Manole, 1992.

MARTINS, CO; MICHELS, G. Saúde X Lucro: Quem Ganha com um Programa de Promoção da Saúde do Trabalhador?Revista Brasileira de Cineantropometria Desempenho Humano, 3(1), 95-101, 2001.

NASCIMENTO, NM, MORAES, RAS. Exercícios Laborativos. In NASCIMENTO, NM, MORAES, RAS, Fisioterapia nas empresas (pp.153- 202). Taba Cultural, 2000.

NOAR, SM; ZIMMERMAN, RS. Health Behavior Theory and Cumulative Knowledge Regarding Health Behaviors: Are We Moving in the Right Direction? Health Education Research, 20(3), 275-290, 2005.

OLIVEIRA, D. L. A 'nova' saúde pública e a promoção da saúde via educação: entre a tradição e a inovação. Revista LatinoAmericana de Enfermagem, 13 (3), 423-31, 2005. 
PASQUALI, L. Testes Referentes a Construto: Teoria e Modelo de Construção. In PASQUALI, L (ed), Instrumentos Psicológicos: Manual Prático de Elaboração. Brasília: LabPAM/IBAPP, 1999.

PASQUALI, L. Análise Fatorial para Pesquisadores. Brasília: LabPAM, 2005.

PEREZ-NEBRA, AR. Medindo a imagem do destino turístico. Dissertação de mestrado. Universidade de Brasília, Brasília, Distrito Federal, Brasil, 2005.

SALLIS, JF; OWEN, N. Ecological Models. In GLANZ, K; LEWIS, FM; RIMER, BK. (eds), Health Behavior and Health Education (pp. 403- 424). San Francisco: Jossey Bass, 1997.

SHEERAN, P; ABRAAM, C. The Health Belief Model. In CONNER, M; NORMAN, P (eds). Predicting Health Behavior (pp 23 - 61). Philadelphia: Open University Press, 1999.

STOKOLS, D. Establishing and Maintaining Healthy Environments. American Psychologist, 47 (1), 6-22, 1992.

WHITING,WC;ZERNICKE, RF. Introdução à Lesão. In WHITING,WC;ZERNICKE, RF, Biomecânica da Lesão Musculoesquelética (pp.1 -13).Rio de Janeiro: Guanabara Koogan, 2001.

Thaís Branquinho Oliveira Fragelli é Fisioterapeuta pela Universidade Estadual de Goiás (UEG) e especialista em Fisioterapia Neurofuncional pela Universidade de Brasília (UnB), mestre em Psicologia Social do Trabalho e das Organizações pela UnB. Lecionou no Centro de Ensino Profissional/ Escola de Música de Brasília ministrando a disciplina Proteção ao Trabalho/ Prevenção a LER/DORT. Realizou palestras e cursos relacionados à prevenção de lesões em músicos. Atualmente é doutoranda em Ciências da Saúde na UnB.

Isolda de Araújo Günther possui graduação em Psicologia pela Universidade Católica de Pernambuco, especialização em Psicologia Clínica pela Universidade Federal de Pernambuco, mestrado em Psicologia Social pela Universidade Federal da Paraíba, doutorado em Psicologia do Desenvolvimento pela Michigan State University, pós-doutorado pela City University of New York e pela Carl von Ossietzky Universität Oldenburg. Atualmente é pesquisadora associada sênior no Instituto de Psicologia da UnB. 


\section{Inventário para avaliação dos determinantes de comportamentos preventivos para músicos (IADCP-MUS)}

Qual a importância, para você, de realizar alongamentos ao tocar seu instrumento?Assinale a alternativa mais compatível com a sua opinião.

1 Discordo totalmente 2.Discordo 3.Nem concordo, nem discordo 4.Concordo 5.Concordo totalmente

\begin{tabular}{|c|c|c|c|c|c|}
\hline & & & & & \\
\hline & 1 & 2 & 3 & 4 & 5 \\
\hline Fazer alongamentos provoca cansaço & & & & & \\
\hline Alongamentos melhoram o desempenho & & & & & \\
\hline Alongamentos são somente para quem tem tempo & & & & & \\
\hline Fazer alongamentos evita o aparecimento de dor & & & & & \\
\hline Fazer alongamentos exige grande esforço & & & & & \\
\hline Alongamentos deixam os músculos flexíveis & & & & & \\
\hline Há redução de estresse quando se faz alongamento & & & & & \\
\hline A dor pode ser causada por alongamentos & & & & & \\
\hline A condição física melhora com alongamentos & & & & & \\
\hline Somente quando se sente dor é necessário alongar & & & & & \\
\hline
\end{tabular}

A Postura corporal é a maneira como se posiciona o corpo para executar o instrumento. Nas afirmações a seguir assinale a alternativa mais compatível com a sua opinião:

1 Discordo totalmente 2.Discordo 3.Nem concordo, nem discordo 4.Concordo 5.Concordo totalmente

\begin{tabular}{|c|c|c|c|c|c|}
\hline & 1 & 2 & 3 & 4 & 5 \\
\hline Ter boa postura corporal ao tocar facilita os movimentos & & & & & \\
\hline Manter uma boa postura corporal ao tocar é cansativo & & & & & \\
\hline Uma boa postura corporal ao tocar evita o aparecimento de dor & & & & & \\
\hline Nem sempre é possivel manter boa postura corporal ao tocar & & & & & \\
\hline 0 desempenho no ensaio melhora quando se adota boa postura corporal & & & & & \\
\hline
\end{tabular}




\begin{tabular}{|l|l|l|l|l|l|}
\hline Sinto dor quando tento melhorar a postura corporal ao tocar & & & & & \\
\hline Ter uma boa postura corporal ao tocar preserva a saúde & & & & & \\
\hline É difícil conciliar a técnica do instrumento com boa postura & & & & & \\
\hline O peso do instrumento dificulta a manutenção de boa postura & & & & \\
\hline O uniforme dificulta os movimentos ao tocar & & & & \\
\hline
\end{tabular}

Os Espaços de ensaio são todos os locais em que você costuma praticar seu instrumento. Com relação aos seus Espaços de Ensaio, indique com que frequência ocorre as seguintes situações:

1 Discordo totalmente 2.Discordo 3.Nem concordo, nem discordo 4.Concordo 5.Concordo totalmente

\begin{tabular}{|c|c|c|c|c|c|}
\hline & 1 & 2 & 3 & 4 & 5 \\
\hline Temos espaço físico para realizar alongamentos no meu local de ensaio & & & & & \\
\hline $\begin{array}{l}\text { A má iluminação do ambiente induz a uma postura corporal inadequada para } \\
\text { conseguir enxergar }\end{array}$ & & & & & \\
\hline A altura da cadeira favorece uma boa postura corporal & & & & & \\
\hline Dividir a estante com outro colega afeta meu conforto físico & & & & & \\
\hline 0 apoio do encosto favorece uma boa postura corporal & & & & & \\
\hline $\begin{array}{l}\text { Partitura de má qualidade induz a uma postura corporal inadequada para } \\
\text { conseguir enxergar }\end{array}$ & & & & & \\
\hline $\begin{array}{l}\text { A acústica do ambiente faz com que eu tenha que me esforçar para conseguir } \\
\text { me ouvir }\end{array}$ & & & & & \\
\hline $\begin{array}{l}\text { A temperatura do ambiente de ensaio deixa minhas articulações mais rígi- } \\
\text { das }\end{array}$ & & & & & \\
\hline $\begin{array}{l}\text { Dividir a estante com outro colega dificulta a manutenção de uma boa postura } \\
\text { corporal }\end{array}$ & & & & & \\
\hline $\begin{array}{l}\text { A proximidade entre os naipes faz com que eu tenha que me esforçar para } \\
\text { conseguir me ouvir }\end{array}$ & & & & & \\
\hline A altura das estantes pode ser regulada de acordo com a minha necessidade & & & & & \\
\hline 0 espaço entre as cadeiras é suficiente para que eu me sinta confortável & & & & & \\
\hline
\end{tabular}


Assinale a alternativa mais coerente com a sua opinião que se relaciona a este grupo.

1 Discordo totalmente 2.Discordo 3.Nem concordo, nem discordo 4.Concordo 5.Concordo totalmente

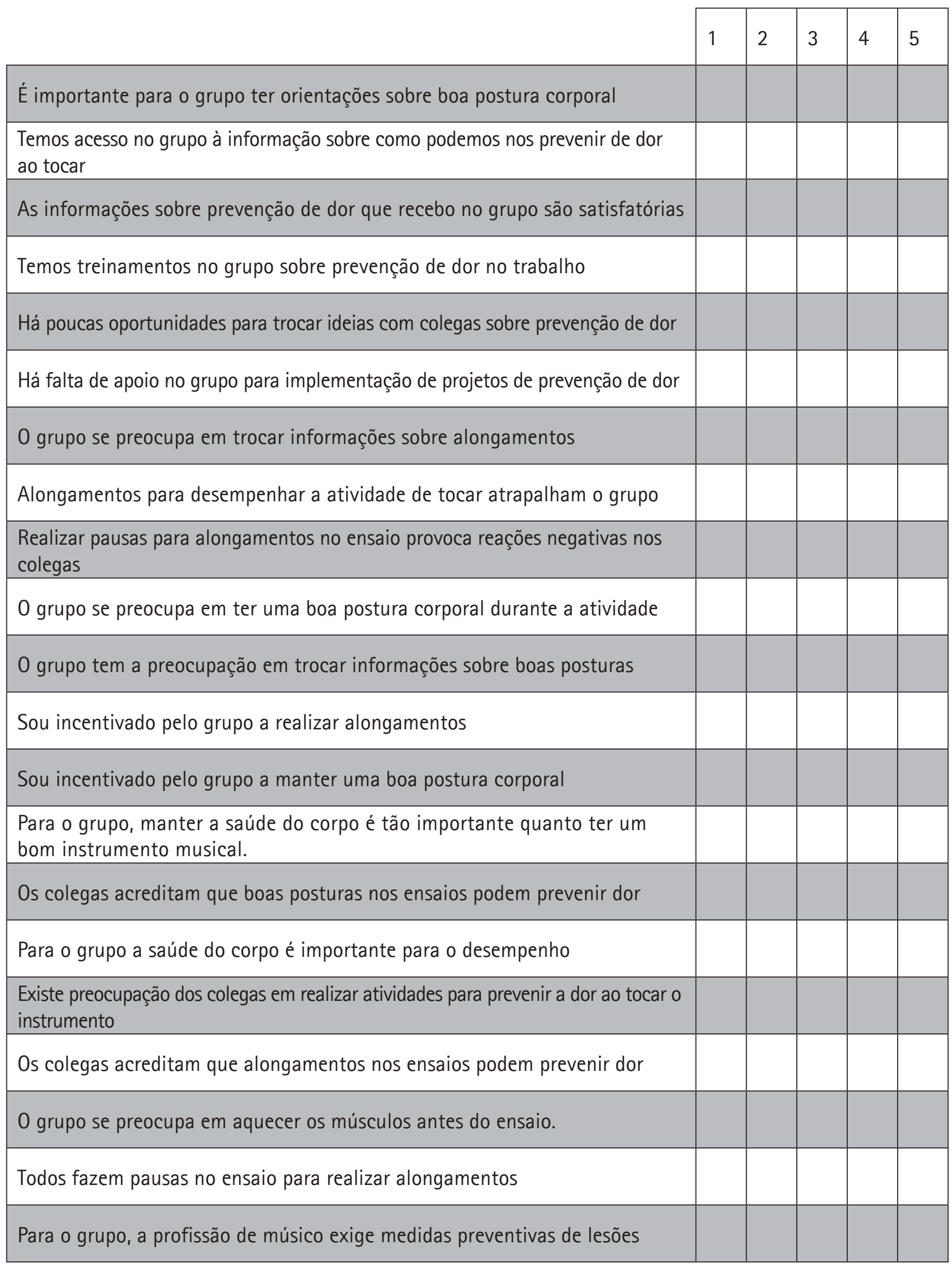

